\title{
Inclusão de deficientes no mundo do trabalho: uma escolha a monitorar
}

\author{
Priscila Turchiello* \\ Fernanda de Camargo Machado**
}

\section{Resumo}

O estudo tem como foco temático a produção da escolha pela inclusão de deficientes, especificamente, no mundo do trabalho. Assim, propóe-se a compreender como vêm sendo mobilizadas ações específicas para incentivar a busca pessoal por participação, justiça, garantia de direitos e eliminação da exclusão de pessoas com deficiência em nossa sociedade. Para tanto, elencou-se como insumo de análise algumas práticas inclusivas realizadas com um aluno deficiente visual, no âmbito de um curso de licenciatura. A partir da noção conceitual e metodológica de "governamentalidade", de Michel Foucault, a pesquisa mostrou como vai se constituindo uma "rede de captura" dos sujeitos com deficiência, de forma a persuadi-los a realizar a "melhor escolha", qual seja, a escolha pela inclusão no mundo do trabalho. $\mathrm{O}$ estudo possibilitou visualizar o empreendimento num conjunto de micropráticas, de forma a manter uma lista de opçôes disponíveis, embora todas conduzam ao mesmo objetivo: incentivar o protagonismo do sujeito na busca de sua própria inclusão.

Palavras-chave: Inclusão; Deficientes; Mundo do trabalho.

* Professora do Instituto Federal Farroupilha, São Borja, Rio Grande do Sul, Brasil.

** Professora doutora do Instituto Federal Farroupilha, Alegrete, Rio Grande do Sul, Brasil. 


\section{Disability inclusion in the labor market: a choice to monitor}

\section{Abstract}

The study has as the mainly purpose the disability inclusion choice, specifically, in the labor market. So, it is proposed to understand how the specific actions have been mobilized to encourage the personal choice to participate, justice and guarantee rights of disabled people exclusion in our society. Therefore, to analyze some inclusion practices accomplished with a visually impaired, as part of a degree course. From the conceptual and methodological notion of "governmentality," Michel Foucault, the research showed how it has been built "capture network" of disabled people, with the purpose to persuade accomplishing the "better choice", namely the inclusion option in the labor market. The study turned possible to visualize the establishment of a set of micro-practices, in a way to keep an available options list, although all conduce to the same goal: to motivate the role of the subject in the search for their own inclusion.

Keywords: Inclusion; Disabled; Labor market.

\section{Do que se trata?}

A questão a ser discutida é a seguinte: precisamos que nos indique possibilidades de trabalho didático metodológico para atender as tuas necessidades, já que o que propomos até o momento não foi recebido de maneira colaborativa. A visão é um sentido que apresentas dificuldades expressivas tendo em vista o teu diagnóstico, sendo assim o que percebemos é a necessidade de investimento em recursos que te permitam potencializar a audição ou o tato. No entanto, parece que nenhuma dessas duas opçôes é aceita por ti, então se torna fundamental que tu nos exponha o que desejas, espera da tua formação, quais as tuas escolhas e opçóes para que possamos pensar em outras estratégias. ${ }^{1}$

Ao iniciarmos este texto com a presente epígrafe, pode parecer que não estamos mostrando nada de novo ou diferente do que tem sido rotina nos espaços escolares na atualidade. Afinal, a inclusão educacional está disseminada nos quatro cantos do país, envolvendo cada vez mais grupos de sujeitos - estejam eles atuando diretamente ou não na escola comum. A inclusão educacional naturalizou-se como processo e promessa do nosso tempo.

Talvez o que nos parece "novidade" é o modo como temos analisado e problematizado as questôes implicadas na operacionalizaçáo das políticas de inclusão educacional no contexto brasileiro. De forma mais pontual, interessa-nos compreender como vêm sendo mobilizadas açóes específicas para incentivar a busca pessoal por participação, justiça, garantia de direitos e eliminação da exclusão de pessoas com deficiência em nossa sociedade.

Nessa tônica, o presente estudo pretende mostrar como vai se implementando uma "rede de captura" dos sujeitos com deficiência, de forma a persuadi-los a realizar 
a "melhor escolha", qual seja, a escolha pela inclusão, especificamente, no mundo do trabalho. Além disso, visualizamos a constituição de práticas de autorreflexão como mecanismos de conexão do sujeito consigo mesmo, produzindo a inclusão como a sua verdade. Para tanto, elencamos como insumo de análise algumas práticas inclusivas realizadas no âmbito de um curso de licenciatura, ofertado por um dos Câmpus de um Instituto Federal, localizado no Estado do Rio Grande do Sul. A materialidade analisada diz respeito a trechos dos diários de bordo do atendimento educacional especializado (AEE) oferecido, semanalmente, ao estudante com deficiência visual incluído no curso de licenciatura. $\mathrm{O}$ que intencionamos apresentar neste artigo não diz respeito a uma analítica que se posiciona como mais verdadeira do que outras, nem mesmo melhor. Trata apenas de algumas de nossas problematizaçóes a respeito de como a inclusão tem sido produzida em diferentes espaços escolares.

\section{Governamentalidade neoliberal, lógica inclusiva e profissionalização de deficientes}

Conforme sinalizado anteriormente, este texto busca apresentar algumas das problematizaçôes que temos tecido em nossos estudos nos últimos anos, e que apresentam como temática central a inclusão social e educacional de pessoas com deficiência e as políticas públicas educacionais que a promovem na atualidade. $\mathrm{O}$ empreendimento de análise, aqui apresentado, não tem como objetivo a avaliação das práticas escolares colocadas em funcionamento na lógica inclusiva contemporânea para considerá-las boas ou ruins, necessárias ou não. Mas tensionar os efeitos produzidos por tais práticas nos modos de vida da população. De forma pontual, buscamos compreender como tem se empreendido uma rede de práticas de incentivo ao desejo por inclusão no mundo do trabalho.

Buscando dar conta de tais intençôes, temos tomado o pensamento de Michel Foucault como lentes teóricas para problematizar o campo educacional. Nossa filiação se refere ao que Veiga-Neto (2005) considera uma filiação "infiel”, já que tomamos alguns conceitos desenvolvidos pelo filósofo, no conjunto de sua obra, como ferramentas analíticas que nos permitem pensar sobre questôes que não foram estudadas pelo autor, indo além do que foi por ele pensado.

Para problematizarmos a inclusão, aqui entendida como um princípio, ou melhor, uma condiçáo indispensável para organização e controle de Estado, optamos pela ferramenta governamentalidade. Cabe salientar, que do lugar que falamos, as ferramentas analíticas não são definidas a priori. Nesse caso específico, a governamentalidade se "encaixa" como utensílio de análise, em virtude de seu potencial para explicar como uma população é construída discursivamente como objeto a estudar, controlar e direcionar. Além disso, na governamentalidade está implicada a dimensão ética do sujeito, ou seja, sua relação consigo mesmo, em práticas de autorreflexão.

O entendimento de Foucault (2008a) sobre a governamentalidade está implicado na compreensáo dos modos de comando das condutas, da vida dos sujeitos que se tramam com as estratégias do Estado, da Economia e da Sociedade. Trata-se de um conjunto de práticas que "tem por alvo principal a população, por principal forma 
de saber a economia política e por instrumento técnico essencial os dispositivos de segurança" (FOUCAULT, 2008a, p. 143).

Tomando a governamentalidade como grade analítica, entendemos que, na contemporaneidade, é importante que os sujeitos tomem a inclusão como princípio regulador de suas condutas, de maneira que haja investimento em si e nos outros para se manterem participantes, incluídos na sociedade. Estudiosos como Lockmann (2013) e Menezes (2011) já evidenciaram em suas pesquisas o elo entre inclusão e governamentalidade. Melhor dizendo, que a inclusão engloba um conjunto de táticas e estratégias voltadas à governamentalidade, ao modo neoliberal de conduzir a população. A inclusão, em tempos de concorrência e estímulo ao autoempresariamento, é uma noção indispensável ao bom funcionamento da engrenagem neoliberal.

Afinal, no momento em que todos e cada um dos sujeitos se negarem a buscar permanentemente a própria inclusão, teremos um sério problema governamental: a não circulação, o que seria um grande e oneroso entrave nos fluxos econômicos, sociais, conjunturais. O neoliberalismo náo sobrevive com sujeitos imóveis; ele necessita de movimento. Para tanto, convencer a massa populacional como um todo, mas especialmente cada cidadão a traçar seu projeto pessoal de inclusão é uma meta perseguida com afinco na atual racionalidade de governo.

Consideramos ainda que, nessa trama, as instituiçóes escolares têm sido convocadas a operar práticas de diferentes ordens para que todos aqueles que por ela, de alguma forma, passam desenvolvam competências consideradas inclusivas. Algumas dessas práticas e seus efeitos são o que nos interessa analisar.

O que também queremos aqui é mostrar que há um elo entre a noção de inclusão como princípio de governamentalidade e as demandas do mundo do trabalho atualmente. A formação restritamente laboral não atende às exigências do mercado na atualidade, que cada vez mais requer sujeitos proativos, competitivos, autogestores, flexíveis e que apresentem condições de concorrência. A ampliação da oferta de educação superior com a intenção de que os mais diferentes sujeitos tenham condições de se inserir no mundo do trabalho é um crucial exemplo dessa demanda.

No contexto inclusivo, a formação e a inserção no mundo do trabalho são consideradas táticas importantes para garantir condiçôes de participação para todos os sujeitos, pois se considera que "o que está em curso, portanto, reafirma que formação humana e cidadã precede a qualificação para o exercício da laboralidade e pauta-se no compromisso de assegurar aos profissionais formados a capacidade de manter-se permanentemente em desenvolvimento" (BRASIL, 2010, p. 6). Nesta esteira, a inclusão opera na conduçáo da vida da populaçáo de maneira que se possa gerenciar o risco social. Investir em si e no outro para permanecer no jogo se torna interessante na atualidade, para que nos mantenhamos em condiçóes de competitividade, de concorrência.

A sociedade regulada com base no mercado em que pensam os neoliberais é uma sociedade na qual o que deve constituir o princípio regulador não é tanto a troca das mercadorias quanto os me- 
canismos da concorrência. São esses mecanismos que devem ter o máximo de superfície e de espessura possível, que também devem ocupar o maior volume possível na sociedade. Vale dizer que o que se procura obter não é uma sociedade submetida ao efeitomercadoria, é uma sociedade submetida à dinâmica concorrencial. Não uma sociedade de supermercado - uma sociedade empresarial. (FOUCAULT, 2008b, p. 201).

Em convergência com o jogo social contemporâneo, a formação profissional para a inserção no mundo do trabalho tem como público alvo, inclusive, aqueles grupos considerados histórica, social, política e economicamente excluídos, dentre eles as pessoas com deficiência. Para Lopes e Fabris (2013, p. 36), "como uma obra de arte, a educação tem que criar formas de ensino capazes de conduzir os indivíduos a conquistar a independência, o que significa saber se autoconduzir sem infringir padrōes individuais e coletivos", já que, com vistas à produção de um empresário de si mesmo, o investimento educacional na atualidade apresenta como foco o desenvolvimento de habilidades que criem as condiçôes de inclusão competitiva no jogo social, sendo os processos de ensino e aprendizagem posicionados como permanentes, isto é, que devem ocorrer por toda a vida.

\section{Escolhas a direcionar}

$\mathrm{O}$ trecho da ata citado no início deste artigo instiga-nos a pensar que temos a liberdade de escolher, dentre uma cartela de opçôes que nos são oferecidas. Há vários caminhos possíveis, desde que - e aí está o ponto focal - se escolha pela inclusão. Todos os caminhos devem levar à inclusão, em especial no que tange à profissionalizaçâo. Ao estudante com deficiência cabe realizar a melhor escolha para que permaneça incluído no seu espaço de formação e em condiçóes de participar do jogo social e econômico do neoliberalismo, já que cabe a cada um assumir o investimento em si mesmo, em sua conduta. Para tanto, é preciso colocar em funcionamento práticas que produzam no estudante o desejo, a vontade de manter-se no jogo, de estar e permanecer incluído. É para algumas dessas práticas que nos dedicamos nesse trabalho.

Conforme já sinalizamos, é preciso que os sujeitos com deficiência tenham condiçóes de realizar as melhores escolhas na esteira da racionalidade política em funcionamento. A inclusão é posicionada nos discursos "oficiais" como a promessa de um país mais justo e igualitário, servindo a formação profissional como ferramenta para amenizar a "ameaça da exclusão".

Buscando atender a estes objetivos, são criadas uma série de microestratégias, a partir da gestão de açôes educacionais específicas, para ampliar as condiçôes de acesso, permanência e êxito de todos os estudantes. No que diz respeito à inclusão escolar de pessoas com deficiência, são colocadas em funcionamento práticas de ordem pedagógica aliançadas a outras áreas de saber como a psicologia e a medicina, que buscam potencializar as experiências de ensino e aprendizagem deste público, de maneira que sejam desenvolvidas as competências necessárias à participação social: 
Analisando o histórico escolar do aluno foi possivel verificar que antes de sua entrada na instituição já havia certo investimento em estratégias pedagógicas e clinicas para o atendimento das necessidades decorrentes de seu diagnóstico. Partindo destas referências, passou-se a buscar mais informaçóes a respeito dos espaços que o estudante frequenta e dos profissionais que lhe atendem, com a intenção de agregar açóes em prol de sua inclusão no ensino superior. (DIÁRIOS, 2015, p. 2).

Investir no fortalecimento desta rede de captura do sujeito com deficiência se torna produtivo, para que, por diferentes vias, haja o investimento no sujeito, e deste em si mesmo para o atendimento dos propósitos inclusivos. As alianças produzidas entre os diferentes especialistas que atendem o estudante fazem circular discursos, os quais indicam modos mais favoráveis do sujeito se relacionar com a formação, a profissionalização e de investir na sua inserção no mundo do trabalho.

De acordo com o estudo de Arnold (2006, p. 150), "é no espaço do risco social que os especialistas e serviços de apoio aparecem ocupando lugar. Um espaço em que a produção de estratégias de prevenção se torna necessária quando a política se volta para o controle do risco". Para tanto, quando se trata de investir sobre o estudante com deficiência, prevenindo o risco de não permanecer incluído, os especialistas ocupam o lugar de quem pode orientar sobre como "melhor" conduzir suas açóes.

Entendemos que, a partir dos investimentos específicos na produção do desejo de estar e permanecer incluídos, os sujeitos com deficiência têm sido capturados por redes de saber. A partir da observação de certas características por parte dos estudantes, aqui em especial do estudante com deficiência visual, vão se gestando açôes educacionais específicas, como o encaminhamento a avaliaçóes clínicas, solicitação de apoio psicológico, verificação de serviços especializados no âmbito municipal, acompanhamento assistencial e provisão de recursos acessíveis:

Ao entrar em contato com alguns profissionais que acompanham o estudante, foi possivel considerar que o mesmo tem recebido atendimento educacional especializado desde a emissão de seu diagnóstico clínico. Segundo as informaçóes repassadas, o referido atendimento tem apresentado como foco o desenvolvimento de habilidades de locomoção $e$ independência, e o aprendizado do Braille. De acordo com o estudante, não apresenta dificuldades em se locomover com autonomia nos locais que já frequenta há algum tempo, fazendo uso da bengala apenas para ser identificado na rua como deficiente visual. Com relação às aulas de Braille, o estudante declara não ter se envolvido nos últimos anos de maneira efetiva, mas que passará a participar mais das mesmas já que lhe afirmam a importância deste aprendizado. (DIÁRIOS, 2015, p. 3).

O excerto acima explana o quanto uma série de caminhos vai sendo proposta ao aluno, de forma a incentivá-lo a buscar sua inclusão. Não se trata de dizer que é uma responsabilização apenas do sujeito com deficiência, mas que este deve se apropriar do discurso inclusivo. O processo de empreendimento sobre si mesmo, 
desenvolvendo habilidades que possam garantir ou ampliar suas possibilidades de inclusão, é o "novo" objetivo desse discurso.

Afinal, nesse caso, o acesso já foi possibilitado; é preciso garantir a permanência, ou melhor, a não exclusão pós-inclusão, produzida pela retenção ou evasão. Para tanto, todos os passos realizados pelo sujeito são monitorados pelas redes de captura, de forma a conduzir suas escolhas:

Após a verificação de que o estudante não tem realizado o acompanhamento oftalmológico que lhe foi recomendado, realizou-se o encaminhamento para avaliaçáo clínica especializada por meio do estabelecimento de parceria com o serviço único de saúde (SUS) do município, solicitando-se um parecer descritivo de suas condiçóes de percepção visual. Contudo, o aluno não compareceu ao agendamento conforme documento encaminhado à instituição pelo serviço municipal. (DIÁRIOS, 2015, p. 6).

Traversini e Bello (2009), ao discutirem a importância da produção de saberes sobre a população a partir de dados, índices, medidas e registros, consideram que "os saberes construídos por diferentes instituiçóes e experts, com base em dados coletados, em registros, em comparaçóes, subsidiam decisóes administrativas para manter e otimizar as características desejáveis da população" (p. 137). O que nos ajuda a pensar que manter em permanente atualização as informaçóes sobre o sujeito torna-se interessante para a produção de saberes que permitirão a gestão de açôes específicas. Trata-se de estratégias para melhor dirigir os sujeitos, otimizando condutas individuais e coletivas, cada vez mais regidas pela lógica neoliberal.

Considerando que no contexto neoliberal a participação nos jogos sociais e de mercado é fundamental, torna-se importante que os sujeitos deficientes optem pela inclusão como possibilidade de contribuir para alavancar seu próprio potencial, bem como o desenvolvimento do país. E, neste texto, entendemos a formação profissional do sujeito com deficiência como uma estratégia interessante para favorecer a inserção no mundo do trabalho com qualificação, condiçôes de concorrência e competição.

Neste sentido, não basta possibilitar o preenchimento de uma vaga no ensino superior, com a promessa de inclusão futura no mundo do trabalho. É preciso constituir uma teia de acompanhamento para vigiar como isso vem ocorrendo, de forma a evitar que esse investimento venha a não ser assumido pelo sujeito com deficiência:

Em conversa com o estudante, tratou-se do relato apresentado pelos docentes do curso em relação às atividades que têm sido propostas em caráter de apoio pedagógico e as percepçóes dos profissionais acerca dos resultados verificados. Segundo o estudante, o trabalho individualizado ofertado permite que ele possa melhor compreender os conteúdos, contudo considera cansativo quando os docentes fazem leituras ou então the disponibilizam áudios. Ao ser questionado sobre que outras possibilidades didático-metodológicas poderia indicar, o estudante não respondeu. Indagado sobre suas condiçóes para realizar a leitura e escrita por meio de recursos especificos como lupas e computador adaptado, 
a resposta foi que não sabe ler e escrever muito bem, já que a muito tempo não realiza essas açóes. Quanto ao uso de tecnologias, relata nunca ter aprendido e ter muitas dificuldades. Ao fim da conversa, o estudante expöe que gosta é de fazer contas, mas que não sabe realizar a maioria delas e que deseja aprender a fazê-las. Ao ser questionado sobre o curso ser de licenciatura, a resposta é de que sabe disso, no entanto está frequentando porque gosta de cálculos. (DIÁRIOS, 2015, p. 4).

Consideramos, ainda, que no curso da governamentalidade neoliberal, o automonitoramento é uma das esferas mais eficazes de condução. Nessa lógica, torna-se indispensável orientar o sujeito a pensar sobre ele mesmo e como vem direcionando seu próprio trajeto inclusivo:

$O$ atendimento do estudante foi direcionado à verificação de como ele tem analisado sua presença no curso de licenciatura. Foram expostas diferentes situaçôes verificadas e relatadas, tais como: não realização de atividades em sala de aula e de avaliaçóes; pouca disponibilidade para participar das açóes propostas no atendimento educacional especializado; falta de interesse no uso dos recursos e tecnologias assistivas; reclamaçôes constantes sobre a impossibilidade de realizar o proposto devido à falta de conhecimentos prévios; solicitação de atividades elementares e que não atendem às exigências da formação em nivel superior. A partir disso, solicitou-se ao estudante que falasse a respeito do que deseja em sua formação, seus objetivos e o que considera necessário para que seu processo de escolarização seja potencializado, já que as dificuldades observadas têm sido significativas e implicam em resultados desfavoráveis no que diz respeito à construção de conhecimentos necessários à inserção profissional. A exposição do estudante não deixa claro que sua intenção é a formação para atuar como docente, já que considera sua opção pelo curso uma possibilidade de aprender cálculos, o que muitos dizem que ele sabe fazer muito bem, já que apesar de ter perdido parte da visão consegue pensar com rapidez. Quanto ao que lhe é ofertado, em termos de apoio, relata que irá se esforçar mais e que investirá nos estudos a partir de agora, algo que considera náo ter feito no decorrer de sua escolarização. (DIÁRIOS, 2015, p. 8).

Por meio dos diferentes momentos, em que o estudante é convocado a pensar e falar a respeito da sua formação, percebemos a operação de táticas que o levam a olhar para as relações que estabelece consigo mesmo, buscando certa disposição de modificar a si. Ao analisarmos as possibilidades de conexão do sujeito consigo mesmo a partir dos discursos inclusivos, convergimos com o pensamento de que

Cada sujeito precisa convencer-se de que é responsável por aquilo que lhe acontece, cabendo-lhe, portanto, desenvolver a capacidade de fazer boas escolhas. E, ainda, ao fazê-las, deverá conscientizarse que as mesmas poderão determinar aquilo que acontece com aqueles com quem convive e, também, com a vida da população de uma forma geral. (MACHADO; MENEZES, TURCHIELLO, 2012, p. 9). 
Da maneira como entendemos a inclusão envolta pelos princípios neoliberais, é imprescindível que os sujeitos aprendam que sua participaçấo ativa na sociedade é fator importante para garantir o chamado pelo progresso do país e a segurança da populaçáo. Sendo assim, participar ativamente exercendo a cidadania e democracia, potencializa a economia política do poder na lógica neoliberal. O que aqui consideramos é que essa economia permite uma diluição do poder sem que haja com isso diminuição do governamento da população que se quer controlar. No excerto que segue, podemos perceber de que maneira os discursos oficiais colocam em funcionamento o recrutamento de todos para a participaçáo dentro de uma racionalidade de Estado neoliberal:

\begin{abstract}
Em síntese, esse novo desenho constituído traz como principal função a intervenção na realidade, na perspectiva de um país soberano e inclusivo, tendo como núcleo para irradiação das açóes o desenvolvimento local e regional. O papel que está previsto para os Institutos Federais é garantir a perenidade das açóes que visem a incorporar, antes de tudo, setores sociais que historicamente foram alijados dos processos de desenvolvimento e modernização do Brasil, o que legitima e justifica a importância de sua natureza pública e afirma uma educaçáo profissional e tecnológica como instrumento realmente vigoroso na construçáo e resgate da cidadania e da transformação social. (BRASIL, 2010, p. 21).
\end{abstract}

Os investimentos em âmbito educacional dizem respeito à operação de práticas sobre os sujeitos ditos em inclusão buscando a gerência do risco de não participarem do jogo social, isto é, de acabarem excluídos. Nesta esteira, visualizamos que as práticas de sensibilização para a inclusão escolar das próprias pessoas com deficiência na contemporaneidade têm apresentado funcionalidade em torno do que entendemos como mobilização de todos e de cada um, em torno da efetivação dos pressupostos das políticas de inclusão educacional no país.

\title{
Considerações finais
}

Todos buscam sua própria inclusão. Antes disso, todos devem querer sua inclusão e gerenciar seu projeto pessoal inclusivo. Se essa é a lógica, ou seja, se nos produzimos sujeitos governados pela perspectiva de que a inclusão educacional permitiria adentrar e sorver os benefícios do mundo do trabalho, faz-se necessário organizar uma série de práticas que convençam do papel de cada um para atingir esse propósito.

Mesmo que a participação de cada um ocorra de diferentes formas, na racionalidade inclusiva o fundamental é não deixar de fazer parte do jogo neoliberal. Nesse sentido, há todo um investimento, que opera sobre todos e cada um, conduzindo modos de vida produtivos, concorrenciais e inclusivos.

Se após o acesso, é preciso garantir a permanência do sujeito, as práticas criadas em torno desse argumento central - a vantagem de investir na própria inclusão com vistas à profissionalização - precisam ser de variadas ordens. Neste estudo, 
miramos na constituição daquilo que chamamos de "rede de captura", que sintoniza especialistas e serviços de diferentes campos de saber. Essa teia, que no caso do estudante em análise era composta por especialistas tanto da saúde quanto da educaçáo, consiste num grande aparato de conduçáo.

Sendo a inclusão educacional um complexo labirinto a ser trilhado, é preciso direcionar esse sujeito a escolher "adequadamente". Ele deve aprender a escolher os melhores recursos didáticos, os melhores métodos de aprendizagem, de forma a potencializar suas melhores habilidades. Neste sentido, o que buscamos mostrar diz respeito à produtividade de açôes educacionais específicas, que, por meio de diferentes táticas, capturam o estudante com deficiência e investem no desenvolvimento do que se considera uma "subjetividade inclusiva" (MENEZES, 2011).

Outra tática condutiva diz respeito à reflexão, pelo próprio aluno, dos investimentos canalizados na sua inclusão. O desejo por permanecer incluído deve ser tão forte quanto o desejo pelo acesso. Afinal, enquanto princípio de governamentalidade, a inclusão abrange essa tríade: acesso-permanência-participação de todos, em todos os espaços sociais.

A partir deste estudo, visualizamos o quanto estamos focados nas práticas que miram a permanência. Sugerimos que, após a conquista da ampliaçáo das possibilidades de acesso, empreender sobre o sujeito, de forma a orientá-lo a gerir melhor suas escolhas de inclusão, vem sendo um importante estratagema na atualidade.

\section{Referências}

ARNOLD, D. K. Dificuldade de aprendizagem: o estado de corrigibilidade na escola para todos. 2006. Dissertação (Mestrado em Educação) - Universidade do Vale do Rio dos Sinos: São Leopoldo, 2006. 172 p.

BRASIL. Ministério da Educação. Um novo modelo em educação profissional e tecnológica. Concepção e Diretrizes. Brasília, DF, 2010. 43 p.

DIÁRIOS de bordo do atendimento educacional especializado (AEE). [S.l.: s.n.], 2015. 10 p.

FOUCAULT, M. Segurança, Território, Populaçáo. Curso dado no Collège de France (1977- 1978). Tradução de Eduardo Brandão. São Paulo: Martins Fontes, 2008a. 572 p.

Nascimento da Biopolítica. Curso dado no Collège de France (1978-1979). Tradução de Eduardo Brandão. São Paulo: Martins Fontes, 2008b. 474 p.

LOCKMANN, K. A proliferaçáo das Políticas de Assistência Social na educaçáo escolarizada: estratégias da governamentalidade neoliberal. 2013. Tese (Doutorado em Educação) - Universidade Federal do Rio Grande do Sul. Porto Alegre, 2013. 317 p.

LOPES, M. C. L.; FABRIS, E. T. H. Inclusão \& Educação. Belo Horizonte: Autêntica, 2013. 127 p.

MACHADO, F. de C.; MENEZES, E. da C. P. de; TURCHIELLO, P. Cidadania e democracia: estratégias da governamentalidade neoliberal para a produção de práticas (de si) inclusivas. In: Educação, cultura, pesquisa e projetos de desenvolvimento: o Brasil do século XXI, 2012, Porto de Galinhas. Anais da 35a Reuniáo Anual da ANPED. Porto de Galinhas: Associação Nacional de Pós-Graduação e Pesquisa em Educação, 2012. CD ROM. 15 p.

MENEZES, E. da C. P. de. A maquinaria escolar na produçáo de subjetividades para uma sociedade inclusiva. 2011 Tese (Doutorado em Educação) - Universidade do Vale do Rio dos Sinos. São Leopoldo, 2011. $189 \mathrm{p}$.

TRAVERSINI, C. S.; BELLO, S. E. L. O numerável, o mensurável e o auditável: estatística como tecnologia para governar. In: Educaçáo \& Realidade. v. 34, n. 2, p. 135-152. Porto Alegre, mai/ago. 2009. 17 p. 
VEIGA-NETO, A. Foucault \& a Educaçáo. 2. ed. Belo Horizonte: Autêntica, 2005. 191 p.

.; LOPES, M. C. Inclusão e Governamentalidade. In: Educaçáo \& Sociedade. vol. 28, n. 100 - Especial, p. 947-963. Campinas, out. 2007. 16 p.

\section{Nota}

${ }^{1}$ A epígrafe trata do recorte da ata de uma das reunióes com a coordenaçáo de curso, professores, aluno e direção do Câmpus de um Instituto Federal localizado no Estado do Rio Grande do Sul, em que se vivenciam processos de inclusão educacional. Convém destacar que todos os excertos analisados nesse artigo estẫo convencionados no padrão itálico.

\section{Correspondência}

Priscila Turchiello - Instituto Federal Farroupilha, Campus São Borja. Rua Otaviano Castilho Mendes, n 355, Betim. CEP: 97670-000 - São Borja, RS - Brasil.

E-mail: priscilaturchiello@gmail.com - nandadecm@yahoo.com.br

Recebido em 15 de junho de 2015

Aprovado em 05 de agosto de 2015 